\title{
Radiographic Quality of Root Canal Filling Performed by House Officers at A Teaching Institute in Karachi, Pakistan
}

\author{
Azam Muhammad Aliuddin ${ }^{1}$ \\ BDS \\ Jabeen Zafar Ali \\ BDS \\ Abubakar Sheikh ${ }^{3}$ \\ BDS, FCPS \\ Saqib Rashid ${ }^{4}$ \\ BDS, MSc, FCPS \\ Muhammad Ali \\ BDS, MCPS \\ Faryal Abdullah ${ }^{6}$ \\ BDS, DCPS
}

OBJECTIVE: The outcome of endodontic treatment is dependent on many factors, but the success of endodontic treatment depends primarily on the quality of the obturation. The objective of this research was to analyze the standard of obturation and to recognize the iatrogenic errors on periapical radiographs and also to equate between the caliber of endodontic treatment and procedural errors executed by male and female house officers.

METHODOLOGY: This was a cross sectional study in which data of 350 treated root canal fillings radiographs along with their proforma showing demographic variables with the name of house officers who treated the patients were assessed. All 350 periapical radiographs were taken from a single institute Fatima Jinnah Dental College Karachi Pakistan from the year 20142016. All endodontic treatments were performed by house officers using crown down technique by hand instrumentationand for each tooth, three periapical radiographic images were assessed. Two calibrated investigators assessed the radiographs for quality and procedural errors. The sample size was calculated using the WHO Calculator and the results were evaluated using chi-square test. SPSS version 21 was used to analyze the results.

RESULT: Overall $122(35 \%)$ of radiographs were up to the acceptable quality as per quality parameters. Gouging and apical perforations were the most common procedural errors found on periapical radiographs. Overall male house officers have performed an acceptable degree of obturation. Chi-square analysis was used to assess the results. CONCLUSION: Gouging and apical perforations were the most common procedural errors found on periapical radiographs. Overall male house officers have performed better quality of root canal filling in anterior, premolar and molar tooth and overall $122(35 \%)$ of radiographs were up to the acceptable quality as per quality parameters.

KEY WORDS: Procedural errors, radiographic quality, house officers, teaching institute

HOW TO CITE: Aliuddin AM, Ali JZ, Sheikh A, Rashid S, Ali M, Abdullah F. Radiographic quality of root canal filling performed by house officers at a teaching institute in karachi, pakistan. J Pak Dent Assoc 2019;28(2):55-62.

DOI: https://doi.org/10.25301/JPDA.282.55

Received: 06 November 2018, Accepted: 26 January 2019

\section{INTRODUCTION}

$\mathrm{T}$ he result of endodontic treatment is based on many factors, but the technical quality of root canal filling is one of the main factors in the success of root canal

1. FCPS Resident, Department of Operative Dentistry, Fatima Jinnah Dental College, Karachi, Pakistan.

2. Demonstrator, Department of Endodontics, Fatima Jinnah Dental College, Karachi, Pakistan.

3. Associate Professor, Department of Endodontics, Fatima Jinnah Dental College, Karachi, Pakistan.

4. Professor, Department of Operative Dentistry, Fatima Jinnah Dental College, Karachi, Pakistan.

5. Assistant Professor, Department of Operative Dentistry, Fatima Jinnah Dental College, Karachi, Pakistan.

6. Senior Registrar, Management and Medical Education (Health Care System Management), Fatima Jinnah Dental College, Karachi, Pakistan. Corresponding author: "Dr Azam Muhammad Aliuddin”> azam_aliuddin@yahoo.com> treatment. ${ }^{1}$ Root canal treatment is one of the primary forms of therapy provided as part of oral health care. ${ }^{2}$ Many studies have revealed a low percentage of technically sufficient root fillings, $45 \%$ was recorded by Ahmed et al. ${ }^{3}$

Different techniques used to control the end result of root canal treatment are mostly established on radiographic assessment. ${ }^{4}$ The outcome of root canal treatment is affected by the extent of root canal filling compared to the radiographic apex..$^{5}$ Less dense and non-homogenous root canal fillings adversely affect the result of root canal treatment. ${ }^{6}$ Procedural faults affect the root canal cleaning and shaping procedure causing deficient root canal filling, which compromises the effectiveness of the treatment. ${ }^{7}$

Several studies have been performed previously to 
determine the quality of root canal treatment such as Dadresanfar and co-authors determined that the technical quality of root canal treatment performed by undergraduate dental students using step-back preparation and cold lateral condensation was adequate in $32.5 \%$ of the cases. ${ }^{8} \mathrm{H}$. Balto and co-author demonstrated that the technical quality of root fillings performed by undergraduate dental students were classified as acceptable in $23 \%$ of cases. ${ }^{9}$ Saeed Muradi and a co-author reported radiographic quality of root canal treatment performed by 6 th year undergraduate students were classified as acceptable in 38\% of cases in Mashhad, Iran. ${ }^{10}$

A review of the treatment quality and frequency of various procedural errors can guide us to formulate better educational programs and clinical teaching methods which will lead to an improvement of the quality of root canal treatment. Literature shows that few local studies have been conducted in our population, the most recent ones being by Fayyaz et al and Ahmed et al. ${ }^{11,3}$ This gives us a strong rationale to conduct this study. The purpose of this study was to evaluate the quality of root canal filling and to identify the iatrogenic errors on periapical radiographssuch as ledge formation, furcation perforation, fractured instrument, strip perforation, apical transportation, apical perforation, gouging, missed canal and zipping in cases treated by house officers at Fatima Jinnah Dental College Karachi, Pakistan. Furthermore, a comparison between the quality of the root canal treatment and procedural errors performed by male and female house officers was also made.

\section{METHODOLOGY}

In this cross sectional study, we investigated radiographic records of 350 obturations done by house officers at Fatima Jinnah Dental College, Karachi, Pakistan between the years of 2014-2016. An approval from the institutional ethical review committee was taken (BEH NO. OCT-2016-OPR01). Inclusion criteria were patients of either sex between the ages of 18 and 65 years. Three periapical radiographs were done during the whole treatment. These included the preoperative, working length and postoperative radiographs. Exclusion criteria were the cases with missing radiographs or radiographs that did not allow proper evaluation due to poor imaging or processing technique and superimposition of anatomical structures, retreated cases and those where endodontic treatment was not completed. Sample calculation was done using WHO Calculator.

All RCTs were carried out by house officers with crown down technique using hand instrumentation and irrigation with $2.5 \%$ sodium hypochlorite solution. An aseptic technique with rubber dam isolation was used in all cases. Working

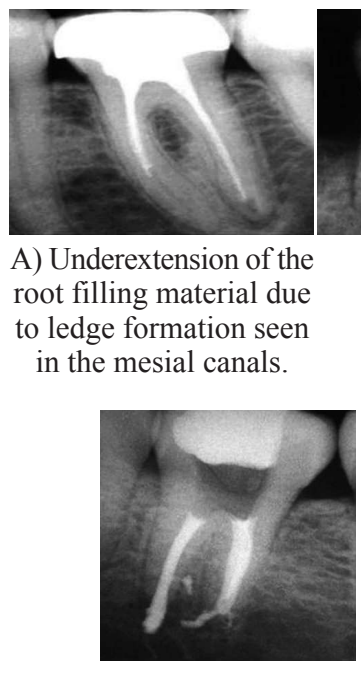

D) Over extension of root filling material

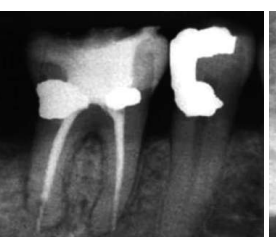

B) Apical perforation

C) Underextension of the root filling material and missed canals. length was established by using digital radiographs (DIGORA), followed by cleaning and shaping. Root fillings were performed with the lateral compaction technique using gutta purcha and calcium hydroxide based sealer (SEALAPEX). For each tooth, the three periapical radiographs were assessed: preoperative, working length confirmation, and postoperative.

Two investigators assessed the immediate post-operative radiographs separately and evaluated whether the radiographic quality of root filling was adequate or inadequate. The standard of root filling length was evaluated radiographically in relation to the radiographic apex, and density was evaluated based on the presence of voids. Any observed under extension and over extension of obturation, presence of voids and insufficient taper was termed inadequate. Acceptable quality was described as appropriate length, adequate density and taper with the exclusion of iatrogenic errors as categorized by Khabbaz et $\mathrm{al}^{12}$ as shown in Table 1 . Previous studies by Balto et $\mathrm{al}^{9}$ and Vukadinov et $\mathrm{al}^{2}$ have also used a similar criteria for judging adequacy of the root filling material and procedural errors. Any procedural faults evaluated on the radiographs were counted as unacceptable root canal fillings and assessment of radiographs were done according to the criteria used by Khabbaz et $\mathrm{a}^{12}$ as shown in Table 2. In cases of disagreement amongst the investigators, a third experienced investigator was requested to evaluate the radiograph and a consensus was reached. In cases where multi-rooted teeth were under evaluation, the overall quality was termed inadequate if one single canal had unacceptable root filling or any procedural error was noted in a single canal.

The results were analyzed by using SPSS version 21.0 for windows. Chi-square test was used to statistically analyze variations between the technical standard and also iatrogenic 
Aliuddin AM/ Ali JZ/ Sheikh A/ Rashid S/ Ali M/ Abdullah F

The criteria to judge quality of endodontic treatment were as follows:

\begin{tabular}{|c|c|c|}
\hline Parameter & Criteria & Assessment \\
\hline Length of root canal filling & $\begin{array}{l}\text { Adequate } \\
\text { Over } \\
\text { Under }\end{array}$ & $\begin{array}{l}\text { Root filling ending }<2 \mathrm{~mm} \\
\text { short of the radiographic } \\
\text { apex. } \\
\text { Obturation exceeding the } \\
\text { radiographic apex. } \\
\text { Root filling ending }>2 \mathrm{~mm} \\
\text { short of radiographic apex. }\end{array}$ \\
\hline Density of Root canal filling & $\begin{array}{l}\text { Adequate } \\
\text { Poor }\end{array}$ & $\begin{array}{l}\text { Consistent density of root } \\
\text { filling and absence of any } \\
\text { voids in canal space. } \\
\text { Non homogenous density of } \\
\text { root filling with clear } \\
\text { existence of voids in canal. }\end{array}$ \\
\hline Taper & $\begin{array}{l}\text { Adequate } \\
\text { Inadequate }\end{array}$ & $\begin{array}{l}\text { Constant taper from the } \\
\text { orifice to the apex. } \\
\text { Non homogenous taper } \\
\text { from the orifice to the } \\
\text { Apex }\end{array}$ \\
\hline
\end{tabular}

Table 1: Criteria to judge root canal filing

The criteria to assess procedural errors were as follows:

\begin{tabular}{|l|l|}
\hline $\begin{array}{l}\text { Ledge } \\
\text { formation }\end{array}$ & $\begin{array}{l}\text { Identified when the obturation was no less than 1 mm } \\
\text { deficient than the primary working length and varied from the } \\
\text { actual canal track in cases with teeth having curved roots. }\end{array}$ \\
\hline Strip perforation & $\begin{array}{l}\text { When the filling material forces out from the outer wall of } \\
\text { multi-rooted teeth. } \\
\text { mesiobuccal roots of maxillary molars, mesial root of } \\
\text { mandibular molar or any root of other teeth. }\end{array}$ \\
\hline Fractured instrument & $\begin{array}{l}\text { Determined when the instrument was discovered within the } \\
\text { root canal or which extends into the periapical region. }\end{array}$ \\
\hline Apical perforation & $\begin{array}{l}\text { Diagnosed when the apical ending of the obturation was } \\
\text { different from the actual canal apex or when the obturation } \\
\text { was extending through the apical foramen. }\end{array}$ \\
\hline Apical transportation & $\begin{array}{l}\text { Detected when the filling material was located on the outside } \\
\text { curve of the canal at the apical third. }\end{array}$ \\
\hline Zipping & $\begin{array}{l}\text { Determined via an elliptical shape of the obturation caused } \\
\text { due to over preparation of the outer wall of the apical } \\
\text { curvature in the canal path. }\end{array}$ \\
\hline Gouging & $\begin{array}{l}\text { Identified bycrown perforations caused due to over extending } \\
\text { the cavity prepand incorrect angulation of the bur resulting in } \\
\text { excessiveremoval of enamel walls. }\end{array}$ \\
\hline
\end{tabular}

Table 2: Criteria to judge procedural errors

mishaps to the tooth type. The significance level was set at $\mathrm{P}<0.05$.
Radiographic quality of root canal filling performed by house officers in Karachi, Pakistan.

\section{RESULT}

Descriptive statistics were enumerated by using SPSS version 21. Stratification was done and post stratification Chi-square test was employed to notice the effect of modifiers on the result. A $p$ value $<0.05$ was taken as significant. The outcome showed that there were 109 male patients and 241 female patients treated by 100 male and 250 female

Table 3: Radiographic quality of root canal filing (Male House Officers VS Female House Officers)

\begin{tabular}{|c|c|c|c|c|}
\hline \multicolumn{5}{|c|}{ House Officer Gender N (\%) } \\
\hline & $\begin{array}{c}\begin{array}{c}\text { Male } \\
(\mathrm{n}=100)\end{array} \\
\end{array}$ & $\begin{array}{l}\text { Female } \\
(\mathrm{n}=250)\end{array}$ & $\begin{array}{c}\begin{array}{c}\text { Total } \\
(\mathrm{n}=350)\end{array} \\
\end{array}$ & P-Value \\
\hline \multicolumn{5}{|c|}{ Root canal Filling Length } \\
\hline Adenuate & $68(35.7 \%)$ & $122(48.8)$ & $190(54.3)$ & \multirow{3}{*}{$\$ 0.05$} \\
\hline Over & $23(23)$ & $92(36.8)$ & $115(32.9)$ & \\
\hline Under & $9(9)$ & $36(14.4)$ & $45(12.9)$ & \\
\hline \multicolumn{5}{|c|}{ Root canal Filling Density } \\
\hline Adequate & $63(63)$ & $131(52.4)$ & $194(55.4)$ & \multirow{2}{*}{0.071} \\
\hline Poor & $37(37)$ & $119(47.6)$ & $156(44.6)$ & \\
\hline \multicolumn{5}{|c|}{ Root canal Filling Taper } \\
\hline Adequate & $70(70)$ & $151(68.3)$ & $221(63.1)$ & \multirow{2}{*}{0.093} \\
\hline Inadequate & $30(30)$ & $99(39.6)$ & $129(36.9)$ & \\
\hline \multicolumn{5}{|c|}{ Root canal Filling Quality } \\
\hline Adequate & $49(49)$ & $73(29.2)$ & $122(34.9)$ & \multirow{2}{*}{$\$ 0.05$} \\
\hline Inadequate & $51(51)$ & $177(70.8)$ & $228(65.1)$ & \\
\hline \multicolumn{5}{|c|}{ Ledge Formation } \\
\hline Present & $9(9)$ & $42(16.8)$ & $51(14.6)$ & \multirow{2}{*}{0.062} \\
\hline Absent & $91(91)$ & $208(83.2)$ & $299(85.4)$ & \\
\hline \multicolumn{5}{|c|}{ Furcation Perforation } \\
\hline Present & $3(3)$ & $13(5.2)$ & $16(4.6)$ & \multirow{2}{*}{0.572} \\
\hline Absent & $97(97)$ & $237(94.8)$ & $334(95.4)$ & \\
\hline \multicolumn{5}{|c|}{ Fractured Instrument } \\
\hline Present & $5(5)$ & $15(6)$ & $20(5.7)$ & \multirow{2}{*}{0.716} \\
\hline Absent & $95(95)$ & $235(94)$ & $330(94.3)$ & \\
\hline \multicolumn{5}{|c|}{ Apical Perforation } \\
\hline Present & $22(22)$ & $94(37.6)$ & $116(33.1)$ & \multirow{2}{*}{ so.05 } \\
\hline Absent & $78(78)$ & $156(62.4)$ & $234(66.9)$ & \\
\hline \multicolumn{5}{|c|}{ Apical Transportation } \\
\hline Present & $7(7)$ & $42(16.8)$ & $49(14)$ & \multirow{2}{*}{90.05} \\
\hline Absent & $93(93)$ & $208(83.2)$ & $301(86)$ & \\
\hline \multicolumn{5}{|l|}{ Gouging } \\
\hline Present & $42(42)$ & $109(43.6)$ & $151(43.1)$ & \multirow{2}{*}{0.785} \\
\hline Absent & $58(58)$ & $141(56.4)$ & $199(56.9)$ & \\
\hline \multicolumn{5}{|l|}{ Zipping } \\
\hline Present & $8(8)$ & $39(15.6)$ & $47(13.4)$ & \multirow{2}{*}{90.05} \\
\hline Absent & $92(92)$ & $211(84.4)$ & $303(86.6)$ & \\
\hline
\end{tabular}


house officers. We found 190 (54\%) adequate results among male and female patients of root canal filling length 68 teeth out of this were treated by male house officers $(36 \%)$ and 122 teeth were by female house officers (64\%). The second criteria of root canal filling density was found to be adequate in 194 (55.4\%) among male and female patients, out of which 63 teeth were treated by male house officers $(32 \%)$ and 131 teeth were treated by female house officers $(68 \%)$. The third criteria of acceptable root canal filling was root canal filling taper which was adequate in $221(63 \%)$ of total results. Out of this 70 teeth were treated by male house officers $(32 \%)$ whereas 151 teeth were treated by female house officers $(68 \%)$. The comparison of root canal filling done

Table 4: Comparison of radiographic quality of root canal filing in various teeth (Anterior teeth VS Posterior Teeth

\begin{tabular}{|c|c|c|c|c|c|}
\hline & & SITE OF TOOTH & $\mathrm{N}(\%)$ & & \\
\hline & $\begin{array}{l}\text { Anterior Tooth } \\
\qquad(\mathrm{n}=56)\end{array}$ & $\begin{array}{l}\text { Pre Molar Tooth } \\
\qquad(\mathrm{n}=118)\end{array}$ & $\begin{array}{l}\text { Molar Tooth } \\
(\mathrm{n}=176)\end{array}$ & $\begin{array}{c}\text { Total } \\
(\mathrm{n}=350)\end{array}$ & P-Yalue \\
\hline \multicolumn{6}{|c|}{ Root canal Filling Length } \\
\hline Adequate & $47(83.9)$ & $73(61.9)$ & $70(39.8)$ & $190(54.3)$ & \multirow{3}{*}{90.05} \\
\hline Over & $8(14.3)$ & $26(22)$ & $81(46)$ & $115(32.9)$ & \\
\hline Under & $1(1.8)$ & $19(16.1)$ & $25(14.2)$ & $45(12.9)$ & \\
\hline \multicolumn{6}{|c|}{ Root canal Filling Density } \\
\hline Adequate & $28(50)$ & $75(63.6)$ & $91(51.7)$ & $194(55.4)$ & \multirow{2}{*}{0.090} \\
\hline Poor & $28(50)$ & $43(36.4)$ & $85(48.3)$ & $156(44.6)$ & \\
\hline \multicolumn{6}{|c|}{ Root canal Filling Taper } \\
\hline Adequate & $40(71.4)$ & $87(73.7)$ & $94(53.4)$ & $221(63.1)$ & \multirow{2}{*}{90.05} \\
\hline Inadequate & $16(28.6)$ & $31(26.3)$ & $82(46.6)$ & $129(36.9)$ & \\
\hline \multicolumn{6}{|c|}{ Root canal Filling Quality } \\
\hline Adequate & $25(44.6)$ & $54(45.8)$ & $43(24.4)$ & $122(34.9)$ & \multirow{2}{*}{90.05} \\
\hline Inadequate & $31(55.4)$ & $64(54.2)$ & $133(75.6)$ & $228(65.1)$ & \\
\hline \multicolumn{6}{|c|}{ Ledge Formation } \\
\hline Present & $2(3.6)$ & $19(16.1)$ & $30(17)$ & $51(14.6)$ & \multirow{2}{*}{$\$ 0.05$} \\
\hline Absent & $54(96.4)$ & $99(83.9)$ & $146(83)$ & $299(85.4)$ & \\
\hline \multicolumn{6}{|c|}{ Furcation Perforation } \\
\hline Present & $0(0)$ & $0(0)$ & $16(9.1)$ & $16(4.6)$ & \multirow{2}{*}{90.05} \\
\hline Absent & $56(100)$ & $118(100)$ & $160(90.9)$ & $334(95.4)$ & \\
\hline \multicolumn{6}{|c|}{ Fracture Instrument } \\
\hline Present & $0(0)$ & $1(0.8)$ & $19(10.8)$ & $20(5.7)$ & \multirow{2}{*}{90.05} \\
\hline Absent & $56(100)$ & $117(99.2)$ & $157(89.2)$ & $330(94.3)$ & \\
\hline \multicolumn{6}{|c|}{ Apical Perforation } \\
\hline Present & $8(14.3)$ & $24(20.3)$ & $84(47.7)$ & $116(33.1)$ & \multirow{2}{*}{90.05} \\
\hline Absent & $48(85.7)$ & $94(79.7)$ & $92(52.3)$ & $234(66.9)$ & \\
\hline \multicolumn{6}{|c|}{ Apical Transportation } \\
\hline Present & $3(5.4)$ & $6(5.1)$ & $40(22.7)$ & $49(14)$ & \multirow{2}{*}{90.05} \\
\hline Absent & $53(94.6)$ & $112(94.9)$ & $136(77.3)$ & $301(86)$ & \\
\hline \multicolumn{6}{|l|}{ Gouging } \\
\hline Present & $20(35.7)$ & $59(50)$ & $72(40.9)$ & $151(43.1)$ & \multirow{2}{*}{0.144} \\
\hline Absent & $36(64.3)$ & $59(50)$ & $104(59.1)$ & $199(56.9)$ & \\
\hline \multicolumn{6}{|l|}{ Zipping } \\
\hline Present & $3(5.4)$ & $5(4.2)$ & $39(22.2)$ & $47(13.4)$ & \multirow{2}{*}{90.05} \\
\hline Absent & $53(94.6)$ & $113(95.8)$ & $137(77.8)$ & $303(86.6)$ & \\
\hline
\end{tabular}

by male and female house officers is shown in Table 3 .

Acceptable root canal filling quality as assessed by three parameters discussed earlier along with absence of procedural errors was found to be $34.9 \%$ out of which $40 \%$ teeth were treated by male house officers and $60 \%$ by female house officers as shown in Table 3.

Adequate root canal filling lengthwas seen in 47(83.9\%) anterior teeth, $73(61.9 \%)$ pre molar teeth and $70(39.8 \%)$ molar teeth. Adequate root canal density was found in $28(50 \%)$ anterior teeth, $75(63.6 \%)$ in pre molar teeth and $91(51.7 \%)$ in molar teeth. Adequate root canal taper was found $40(71.4 \%)$ in anterior teeth, $87(73.7 \%)$ in pre molar teeth and 94(53.4\%) in molar teeth. Therefore overall acceptable root canal filling quality was found in 25(44.6\%) of anterior teeth, 54(45.8\%) of premolar teeth and in $43(24.4 \%)$ of molar teeth as shown in Table 4.

\section{The different procedural errors identified in the root canal filling were as follows:}

Ledge formation: As a quality assessor it was found $14 \%$ in 350 cases. Out of these 51 cases 9 teeth were treated by male house officers and 42 teeth by female house officers. Furcation perforation: The procedural error of furcation perforation was found to be $4.6 \%$ out of which 3 cases were treated by male house officers and 13 by female house officers.

Fractured instrument: This error was found in5.7\% (20) out of which 5 teeth were treated by male house officers and 15 teeth by female house officers.

Apical perforation: This error was found in $33 \%(116)$ out of which 22 teeth were treated by male house officer whereas 94 teethby female house officers.

Apical transportation: This error was found to be $14 \%$ (49), out of which 7 cases were done by male house officer whereas 42 casesby female house officer.

Gouging:This was found in 43\% (151) of total cases out of which 42 teeth were done by male house officer and 109 teeth by female house officers.

Zipping:It was found as a procedural error in $13.4 \%$ (47) cases out of which 8 teeth were treated by male house officers whereas 39 teeth were done by female house officers. No results for strip perforations and missed canals were recorded during our study since no such data for these particular procedural errors could be collected. These results have been shown in Table 3.

\section{DISCUSSION}

Our study demonstrates the radiographic evidence of the nature of root canal fillings and iatrogenic errors executed by male and female house officers at Fatima Jinnah Dental 
Table 5: Comparison of radiographic quality of root canal filing in various teeth performed by male house and female house offeicers

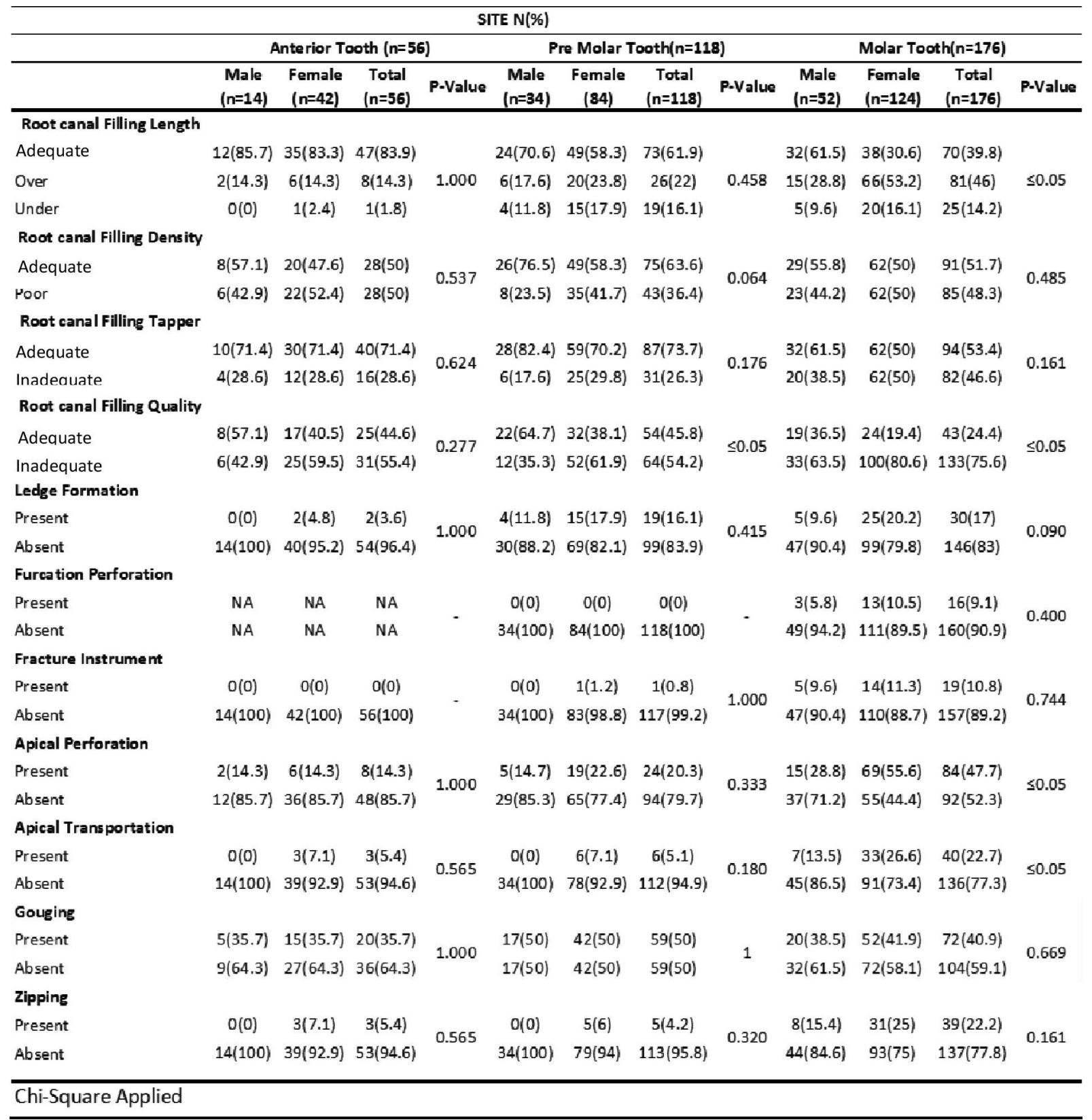

College, Karachi, Pakistan. In most studies, the acceptable root canal filling is considered to be within $2 \mathrm{~mm}$ of the radiographic apex, ${ }^{13,14,15}$ which was noted in our study as acceptable root canal filling with an overall percentage of $34.9 \%$. Various studies have shown differing percentages regarding acceptable root canal fillings such as $76 \%$ reported by Al-Yahya ${ }^{16} 39 \%$ by Dugas $\mathrm{N}$ et $\mathrm{al}^{17} 55 \%$ by Eleftheriadis $\mathrm{G}$ et $\mathrm{a}^{18}$ and $13 \%$ by Hayes $\mathrm{S}$ et $\mathrm{al}^{19}$ however since all these studies have had a different rating criteria, it is hard to establish a true comparison.

In the current study the percentage of acceptable obturations are similar in the anterior and premolar teeth when compared to the study by Boucher Y et al, where the percentage of acceptable root canal fillings is greater in molars unlike our study. ${ }^{1}$ This is primarily attributed to the differing anatomy of the teeth along with lack of experience of the operators. According to our study, the percentage of root canal fillings reaching adequate length is $54.3 \%$, this is lower when compared to Er et $\mathrm{al}^{20}$ and higher when compared to the study reported by Lupi-Pegurier ${ }^{21}$ which have reported $70 \%$ and $39 \%$ respectively. One of the primary reasons for this conflict is that house officers perform 
periapical radiographs with a non-parallel technique and sometimes are unable to judge the length on radiographs. ${ }^{22}$ Secondly, since the periapical radiographs are two dimensional, assessing adequate lengths is problematic. Study by Gordon et al has stated that regular use of an apex locator followed by a confirmatory radiograph using a $\mathrm{K}$-file to determine the working length is a good technique for establishing length of root canals. ${ }^{23}$

The density of adequate root canal filling in our study was reported to be $54.3 \%$, which is comparatively lower than other studies such as Yoldas etal and Sagsen etal which demonstrated $64 \%$ and $92.6 \%$ respectively. ${ }^{24,25}$ No significant association between the tooth type and density of the root filling was established in our study. Kirkevang et al demonstrated that failure of root canal treatment occurs due to poor density of root canal filling. ${ }^{26}$ A 5 year follow up study by Burke et al also concluded that the success rate of an endodontically treated tooth depends on the length and quality of the root canal filling. ${ }^{27}$

The incidence of teeth having adequate taper of the root canal filling was recorded in our study as $63.1 \%$ which when compared to other studies is relatively lower. ${ }^{14,24,25}$ A significant relation between tooth type and adequate taper of obturation was noted in the present study. A study conducted by Ranya FElemam et al, has reported the increased percentage of taper of root filling in anteriors $(87.5 \%)$ and premolars $(81 \%)$ whereas lower percentage in molars (54.5\%) owing to the increased incidence of curved roots and narrow canals..$^{28}$ Our study shows similar findings with taper being greater in the anterior $(71.4 \%)$ and premolar $(73.7 \%)$ region and being less in molars $(53.4 \%)$. This can be attributed to the fact that less skilled operators find it difficult to achieve good taper in molar teeth due to anatomical variations and the fact that reaching adequate working length in curved roots is a difficulty faced by many house officers. Procedural errors are one of the major determinants for long term success of the endodontically treated tooth. In the present study ledge formation during root canal treatment was lower in anterior teeth (3.6\%) and premolar teeth $(16.1 \%)$ as compared to molars (17\%) because molars have a high prevalence of complex root canal anatomy such as narrow and curved canals. The percentage of ledge formation in molars was lower as compared to other studies which reported a higher percentage of ledge formation like those reported by Kapalas $(52 \%)^{29}$ and Eleftheriadis(39\%). ${ }^{18}$ One of the primary reasonsfor the low percentage of ledges in the present study was the use of gates Glidden to straighten the coronal part of the canal, the use of EDTA in curved canals and pre curving of the stainless steel file before cleaning and shaping of curved canals. Apical perforation (33.1\%), apical transportation (14\%) and zipping (13.4\%) were found to be as high as compared to other studies ${ }^{15}$ and there was also significant association with tooth type. These errors more commonly occurred in molars because of complex root canal anatomy and the use of stainless steel files. Several authors have reported that nickel titanium files cause less transportation than stainless steel..$^{30,31}$

In our study, $4.6 \%$ furcation perforation occurred in molars and there was a high percentage of instrument separation/ fracture noted in molars because preparation of curved canals in molars was challenging and was performed by less experienced operators. In the present study gouging occurred in $43.1 \%$ and it was unrelated to the tooth type, but this variable is measured only on radiographs therefore it is not very subjective. However, the results are higher when compared to a study conducted by Hendi SS et al which showed only $3.2 \%$ of cases with gouging. ${ }^{32}$ The results of a study conducted by Mukhaimer RH on undergraduate students were in agreement with the present study with a $4.6 \%$ observed cases of perforation. ${ }^{33}$

The outcome of this study was affected by gender which is different from other studies ${ }^{34,9}$ Out of 350 house officers, the ratio of male to female house officers was $2: 5$. There was a significant difference in acceptable quality of root canal filling among both genders. Male house officers performed root canal treatment with better quality $(49 \%)$ as compared to female house officers which was found to be $29.2 \%$ and similar differences were noted in procedural errors such as in apical perforation, apical transportation and zipping. The study also showed gender wise difference in the quality of root canal among various teeth as indicated in Table 4 and Table 5 which was found to be $64.7 \%$ in premolar teeth done by male house officers and $38.1 \%$ done by female house officers. The difference in quality was found to be $36.5 \%$ done by male house officers and $19.4 \%$ by female house officers performed in molars. This study also revealed that more root canals were overfilled by female house officers $(53.2 \%)$ as compared to male house officers $(28.8 \%)$. This study also highlighted that female house officers performed more apical perforations (55.6\% vs. $28.8 \%)$ and apical transportations ( $26.6 \%$ vs. $13.5 \%)$ in molar teeth as compared to male house officers (Table 3). This may be due to the fact that working hours of male house officers were more and in our set up males attend more educational courses. Male house officers do more attachments therefore exhibit better skill due to more practice. Disparity in results can also be explained by the difference in the number of male and female house officers being assessed.

One of the limitations of the present study wasthat roots of all teeth were scored individually and the tooth was taken as a unit. Errorin one root canal filling in a multi-rooted tooth was considered as failure of whole tooth. Any such 
faults in single rooted teeth will also be considered inadequate and result in failure of the endodontic treatment. Certain errors were not evaluated in this study such as strip perforation and missed canals etc. because periapical radiograph is two dimensional and cannot study different angulations. Acceptable obturations were found to be lower in our study which was consistent with previous studies. This could be because of the technique utilized while performing the root canal treatment. Another reason could be the variability among supervisor to house officer ratio which is usually less in our setup.These results could be re-verified by expanding the study population to other institutes.

Since the prognosis of root canal treatment is a multifactorial phenomenon, judging only the technical quality of obturations, as shown on radiographs, should not be used as the sole determinant of the quality of treatment in general. While such epidemiological studies are critical for research, many key elements of root canal treatment are left unresolved. Efforts to achieve adequate cross infection control, isolation, chemicomechanical debridement and canal preparation along with use of appropriate materials and techniques are all significant components which affect the prognosis of the treatment.

\section{CONCLUSION}

According to our study, procedural errors were more common in posterior teeth when compared to anterior teeth due to anatomical variations. Male house officers tend to have better radiographic obturation quality during endodontic procedures than female house officers.

\section{FINANCIAL SUPPORT AND SPONSORSHIP} Nil.

\section{CONFLICTS OF INTEREST}

There are no conflicts of Interest.

\section{REFERENCES}

1. Boucher Y, Matossian L, Rilliard F, Machtou P. Radiographic evaluation of the prevalence and technical quality of root canal treatment in a French subpopulation. Int Endod J. 2002;35:229-38. https://doi.org/10.1046/j.1365-2591.2002.00469.x

2. Vukadinov T, Blažic L, Kantardžic I, Lainovic T. Technical quality of root fillings performed by undergraduate students: a radiographic study. Sci World J.2014;2014:751274.

https://doi.org/10.1155/2014/751274

3. Ahmed, A., O. Khattak, H. Ali, A. Maqbool, G. Azhar, A. Shamim.
Radiographic technical quality of root canal fillings performed by house surgeons in the Islamic international dental college: a pilot study. Pak Oral Dent J. 2008;28:271-74.

4. Buckley M, Spangberg LS. The prevalence and technical quality of endodontic treatment in an American subpopulation. Oral Surg Oral Med Oral Pathol Oral Radiol Endod.1995;79:92-100. https://doi.org/10.1016/S1079-2104(05)80081-2

5. Sjögren U, Hägglund B, Sundqvist G, Wing K. Factors affecting the long-term results of endodontic treatment. J Endod. 1990;16:498504.

https://doi.org/10.1016/S0099-2399(07)80180-4

6. Chugal NM, Clive JM, Spångberg LS. Endodontic infection: some biologic and treatment factors associated with outcome. Oral Surg Oral Med Oral Pathol Oral Radiol Endod. 2003;96:81-90. https://doi.org/10.1016/S1079-2104(02)91703-8

7. Lambrianidis TP. Risk management in root canal treatment: University Studio Press; 2001.

8. Dadresanfar B, Akhlaghi NM, Vatanpour M, Yekta HA, Mohajeri LB. Technical quality of root canal treatment performed by undergraduate dental students. Iran Endod J. 2008;3:73.

9. Balto H, Al Khalifah S, Al Mugairin S, Al Deeb M, Al-Madi E. Technical quality of root fillings performed by undergraduate students in Saudi Arabia. Int Endod J. 2010;43:292-300.

https://doi.org/10.1111/j.1365-2591.2009.01679.x

10. Moradi S, Gharechahi M. Radiographic quality of root canal treatment performed by 6th year undergraduate students in Mashhad. IranDent Res J. 2014;11:364.

11. Fayyaz A, Ehsan S, Waseem RF. Radiographic evaluation of endodontic treatment performed by undergraduate students and interns. J Pak Dent Assoc. 2018;27:115-19.

https://doi.org/10.25301/JPDA.273.115

12.Khabbaz MG, Protogerou E, Douka E. Radiographic quality of root fillings performed by undergraduate students. Int Endod J. 2010;43:499-08. https://doi.org/10.1111/j.1365-2591.2010.01706.x

13. Er O, Sagsen B, Maden M, Cinar S, Kahraman Y. Radiographic technical quality of root fillings performed by dental students in Turkey. Int Endod J. 2006;39:867-72.

https://doi.org/10.1111/j.1365-2591.2006.01158.x

14. Barrieshi-Nusair K, Al-Omari M, Al-Hiyasat A. Radiographic technical quality of root canal treatment performed by dental students at the Dental Teaching Center in Jordan. J Dent. 2004;32:301-07. https://doi.org/10.1016/j.jdent.2004.01.002

15. Unal GC, Kececi AD, Kaya BU, Tac AG. Quality of root canal fillings performed by undergraduate dental students. Eur J Dent. 2011;5:324.

16. Al-Yahya A. Analysis of student's performance in an undergraduate endodontic's program. Saudi Dent J. 1990;2:58-61. 


\section{Aliuddin AM/ Ali JZ/ Sheikh A/ Rashid S/ Ali M/ Abdullah F}

17. Dugas N, Lawrence H, Teplitsky P, Pharoah M, Friedman S. Periapical health and treatment quality assessment of root-filled teeth in two Canadian populations. Int Endod J. 2003;36:181-92. https://doi.org/10.1046/j.1365-2591.2003.00640.x

18. Eleftheriadis G, Lambrianidis T. Technical quality of root canal treatment and detection of iatrogenic errors in an undergraduate dental clinic. Int Endod J. 2005;38:725-34.

https://doi.org/10.1111/j.1365-2591.2005.01008.x

19. Hayes S, Gibson M, Hammond M, Bryant S, Dummer P. An audit of root canal treatment performed by undergraduate students. Int Endod J. 2001;34:501-05.

https://doi.org/10.1046/j.1365-2591.2001.00421.x

20. Er O, Sagsen B, Maden M, Cinar S, Kahraman Y. Radigraphic technical quality of root fillings performed by dental students in Turkey. Int Endod J. 2006;39:867-72.

https://doi.org/10.1111/j.1365-2591.2006.01158.x

21.Lupi-Pegurier L, Bertrand MF, Muller-Bolla M, Rocca JP, Bolla M. Periapical status, prevalence and quality of endodontic treatment in an adult French population. Int Endod J. 2002;35:690-97. https://doi.org/10.1046/j.1365-2591.2002.00547.x

22. Saunders EM. Hand instrumentation in root canal preparation. Endod Topics. 2005;10:163-67.

https://doi.org/10.1111/j.1601-1546.2005.00127.x

23. Gordon MPJ, Chandler NP. Electronic apex locators. Int Endod J. 2004;37:425-37.

https://doi.org/10.1111/j.1365-2591.2004.00835.x

24. Yoldas O, Topuz A, Isçi AS, Oztunc H. Postoperative pain after endodontic retreatment: single- versus two-visit treatment. Oral Surg Oral Med Oral Pathol Oral Radiol Endod. 2004;98:483-87. https://doi.org/10.1016/j.tripleo.2004.03.009

25. Sagsen B, Er O, Kahraman Y, Orucoglu H. Evaluation of microleakage of roots filled with different techniques with a computerized fluid filtration technique. J Endod. 2006;32:1168-70. https://doi.org/10.1016/j.joen.2006.07.016

26. Kirkevang LL, Hörsted-Bindslev P, Ørstavik D, Wenzel A. A
Radiographic quality of root canal filling performed by house officers in Karachi, Pakistan.

comparison of the quality of root canal treatment in two Danish subpopulations examined 1974-75 and 1997-98. Int Endod J. 2001;34:607-12.

https://doi.org/10.1046/j.1365-2591.2001.00436.x

27.Burke FM, Lynch CD, Ni Riordain R, Hannigan A. Technical quality of root canal fillings performed in a dental school and the associated retention of root-filled teeth: clinical follow up study over a 5 year period. J Oral Rehabil. 2009;36:508-15.

https://doi.org/10.1111/j.1365-2842.2009.01966.x

28. Elemam RF, Abdul Majid ZS, Groesbeck M, Azevedo AF. Quality of Root Canals Performed by the Inaugural Class of Dental Students at Libyan International Medical University. Int J Dent; 2015: Article ID 135120.

https://doi.org/10.1155/2015/135120

29.Kapalas A, Lambrianidis T. Factors associated with root canal ledging during instrumentation. Dent Traumatol. 2000;16:229-31. https://doi.org/10.1034/j.1600-9657.2000.016005229.x

30.Gambill JM, Alder M, Carlos E. Comparison of nickel-titanium and stainless steel hand-file instrumentation using computed tomography. J Endod. 1996;22:369-75.

https://doi.org/10.1016/S0099-2399(96)80221-4

31.Schäfer E, Lau R. Comparison of cutting efficiency and instrumentation of curved canals with nickel-titanium and stainlesssteel instruments. J Endod. 1999;25:427-30.

https://doi.org/10.1016/S0099-2399(99)80272-6

32. Hendi SS, Karkehabadi H, Eskandarloo A. Iatrogenic Errors during Root Canal Instrumentation Performed by Dental Students. Iran Endod J. 2018;13:126-31.

33. Mukhaimer RH. Radiographic technical quality of root canal fillings performed by dental students in Palestine. Indian J Oral Sci. 2013;4:55-63

https://doi.org/10.4103/0976-6944.119927

34. Kerekes K, Tronstad L. Long-term results of endodontic treatment performed with a standardized technique. J Endod. 1979;5:83-90. https://doi.org/10.1016/S0099-2399(79)80154-5 